\title{
Research and Analysis of Current Rural Medical Security Situation in Shizong, Yunnan
}

\author{
Chen Meixia $^{1}$ Zhou Mengjie ${ }^{2}$ \\ ${ }^{1,2}$ School of Public Management, Yunnan University of Economics and Finance, Kunming,, \\ P.R.China, 650221 \\ (E-mail: yngcx@126.com)
}

\begin{abstract}
This paper analyzed Shizong rural medical Security situation in multiple angles. Use questionnaire survey, empirical analysis and cases interview, etc. To finds out that rural areas has limited in the current medical security system. Farmers' medical expense mainly relies on their own family support. Therefore, this paper will discuss and analyze the primary problem in Shizong rural medical security system, and offer rational suggestions to make it easier and cheaper for rural people to see a doctor. In further, those suggestions aim to increase farmers' ability of risk avoidance and make more farms benefit from the government's welfare policy.
\end{abstract}

\section{Key Words: Medical security, rural medical security, security system}

\section{Introduction}

Medical security system is a pivotal part of social security system, the key foundation of construction of socialist market economy system, and one of the composing forms of ensuring people's physical health. From the view point of health care and social security, medical security system is a guarantee system which can provide public the necessary medical service. This security system is consisted by many forms. Medical insurance system is the most vital part of those forms.

Rural medical security is an important part of rural social security system. In order to keep the economic development and social stability, country or government in accordance to law provides material aids to farmers when they suffer from old age, illness, disability, unemployment, disasters, difficult life circumstances, and etc. Therefore, rural medical security can be defined as the integration of all policies that legally made by state and society according to rural areas' current situation in preventing the violation of farmers' basic rights like disease prevention and treatment. Rural medical security includes widely contents, which are medical facilities, medical personnel, medical insurance fund, disease control, maternity and child care, health education and health supervision, etc.

China's cooperative medical has changed along with the economic development and social structure change. The state enacted "the outline for China's rural primary health care program development (2001-2010)", which 
clearly put forward that China will gradually establish a new rural cooperative medical care system (NCMS) based on comprehensive arrangement for serious disease. On January, 2003,"the notice of the opinions of health department in establishing NCMS forwarded by the general office of the state council" stated that NCMS, is a rural medical assistance system which primarily based on comprehensive arrangement for serious disease. It is organized by government and funded through individuals, organizations and government. Rural households can enrolled in NCMS voluntarily. According to this, the level of farmers' medical treatment has improved and especially the aged have support. In further, rural people's living standards and conditions have improved. It's also make Chinese economy benefited.

China is the largest developing country in the world. Its rural modernization process has a great demonstrate effect on the numerous worldwide developing countries. Therefore, the development of China's rural medical cooperative system not only catches the attention of Chinese government, related department and the whole society, but also has significantly international influence. Western social security dated back earlier, and its theory study has been the focal point in the academia.

According to "historical research of China rural cooperative medical security system", Xinzhen Xia argued several aspects from government function, system, specific operation, system environment, by studying rural cooperative medical cases before 1980s. Deyuan Zhang in "the development of China's rural health care" analyzed the vicissitude of cooperative medical system and the development of new rural cooperative medical system. Fang $\mathrm{Li}$ in "problem research of China's rural medical security system reform", analyzed the insufficient of rural medical security, which were serious shortage of public health investment, unreasonable resource disposition, unsound third rural health service network, etc. She also provided theory basis to consummate rural medical security. Yongshun Fan demonstrated the current executive situation of China's new rural cooperative system through empirical study in "analysis and countermeasures of new rural cooperative medical system of Panlong, Kunming". In "rural medical security system development: new rural cooperative medical system", Jianbo Zhou noted that central government should support the low income and high rural population province to establish medical system, especially for the minority and mountainous areas. Liping Gao in "Shandong new rural cooperative medical system investigation" and Guizhi Liu in "Jilin new rural cooperative medical system operation analysis" stated the current operation situation of China's new rural cooperative medical system from multiple aspects through empirical study. The previous scholars mainly focused on the rural medical security system analysis through multiple aspects of content, structure and finance and revealed problems still remaining in China's real rural medical security system from different scopes.

\section{Investigation of rural health care in Shizong}

Shizong, is a county of Qujing, Yunnan, located in the southeast of Yunnan province spanning 2,783 square kilometers and with approximately $90 \%$ mountainous areas. The population of the county is 380 thousands with 
the population density of 137/ square kilometers. The agricultural population is 320500, accounting for $84.34 \%$; the non-agricultural population is 59500, accounting for $15.66 \%$. The terrain of the county is similar to a rabbit, bordering Xilin, huxi, Qiubei, Luliang, and Luopin (Shizong Government data).

According to data provided by Shizong health bureau, 0.85 per thousand population are certificated doctors; 1.2 per thousand population are certificated burse. Compared to 2.2 and 2.0 respectively in Qujing city, Shizong has to increase approximately 400 certificated doctors and 300 certificated nurses. Also, the eight township centers only have 257 staff, which should be 359 staff according to 1 per thousand dispositions. The personnel shortage seriously disturbs the implement of public health service and basic medical service. See Table 1.

\begin{tabular}{|c|c|c|}
\hline \multirow{2}{*}{ Project } & certificate & Number of people \\
\hline \multirow{4}{*}{$\begin{array}{c}\text { Regular technical } \\
\text { personnel }\end{array}$} & $\begin{array}{c}\text { Senior (including } \\
\text { sub-senior) }\end{array}$ & 27 \\
\cline { 2 - 3 } & intermediate & 153 \\
\cline { 2 - 3 } & primary & 219 \\
\cline { 2 - 3 } & Primary physician & 109 \\
\cline { 2 - 3 } & undetermined & 55 \\
\hline \multirow{4}{*}{$\begin{array}{c}\text { Registered health } \\
\text { technical personnel }\end{array}$} & total & 563 \\
\cline { 2 - 3 } & registered (assistant) \\
physicians & 371 \\
\cline { 2 - 3 } & Registered nurses & 476 \\
\cline { 2 - 3 } & $\begin{array}{c}\text { Registered rural } \\
\text { physicians }\end{array}$ & 327 \\
\cline { 2 - 3 } & total & 1174 \\
\hline
\end{tabular}

Table 1: Shizong health care physician personnel statistics

From above data, Shizong County is facing a serve shortage of health care personnel in all areas, especially the professional physicians. These shortages are affecting the quality of rural health care services.

The township health center is the centre of health care network of county, township and village, connecting county hospitals and village clinics. It accepts the referral from village clinics and transfers the serious and difficult ill patients to county hospitals. It guides and manages the village-level institutions' health care and prevention task as well.

However, the present township health center force is at a extremely backward level. It vastly threatens the accessibility of the township basic health care services and medical services. The rural health care weakness is mainly due to the shortage of medical staff and infrastructure construction funds. In villages of Shizong county, private clinics are the primary choices for residents there because of the convenient services, low 
cost and easy procedures. In the survey, 220 questionnaires were given out randomly198, were taken back. The result is shown as below. See Table 2.

\begin{tabular}{|c|c|c|}
\hline $\begin{array}{c}\text { Private clinics } \\
\text { services }\end{array}$ & $\begin{array}{c}\text { Number } \\
\text { of people }\end{array}$ & $\begin{array}{c}\text { Percenta } \\
\text { ge }\end{array}$ \\
\hline convenience & 61 & $30.70 \%$ \\
\hline Less expense & 81 & $40.80 \%$ \\
\hline Easier procedures & 56 & $28.50 \%$ \\
\hline
\end{tabular}

Table 2 : statistics of choosing private clinics in rural areas

In the survey, $42.9 \%$ members prefer to go see a doctor in private clinics, because they are much closer and more convenient. However, those private clinics are usually in extremely poor conditions without enough medical equipments. During the interview, it was observed that almost all the private clinics were in the same condition that was not so normative. Those clinics are usually comprised of two or three rooms, approximately 30-55 square meters in total, with one medicine cupboard and 1-2 beds (those beds are not only for patients but also for the owners to have rest). There is no special drug storage place for those few drugs anyway. Basically couple who runs the clinic are the only staff, with the host as doctor and the hostess as nurse.

\section{The problems of rural medical security system in Shizong}

According to the data showing on previous surveys of rural patient and medical staff, the existing problem of rural medical security system can be shown as below.

\subsection{Rural residents with poor education}

Because of the cognitional problem, many rural residents still do not accept new rural cooperative system. First, the lack of understanding and trust makes rural residents keep distance with the new system. Second, rural residents are unfamiliar with their right and obligations of enrolling the system, which makes them lack of initiative. The last, some residents wrongly think that the medical security system could cover all the disease and expense, which causes their unexpected loss.

In despite of $96.06 \%$ rural population has participated in the new cooperative medical security system, many of them still know little about the content of new system, like their obligations and right, reimbursement amount and management method. The main reason for that is the new system has not been well broadcast, which limits the whole coverage of the new system.

\subsection{Reducing investment on medical equipment}

Under the support of Chinese county government, Shizong County has increased the investment capital of the basic rural health construction and medical devices, which has great influence on developing the rural medial system and solving the rural residents' medical treatment problem. However, with the development of social and rural economy and the increasing need for rural health care, especially after the constructing of new rural cooperative medical security system, the supply of medical services are still not enough, mainly reflects in the short storage of houses and medical devices. The county health care 
institutions as the emergency center and technical guidance center in rural areas, are lack of necessary large medical equipment, especially the public health care devices. Besides, the problem of county clinic construction is even more serious, owing to the long investment shortage by local government.

\subsection{Low quality of medical staffs}

The education background and professional ability of medical staff are not good enough. According to the survey, Shizong present has 563 professional medical technicians from payrolls, 1174 registered professional medical staff, 371 registered professional (or assistant) doctors, 476 registered nurses, 327 registered rural doctors. 79 rural doctors acquiring their university degrees in service and 170 are still studying in the university. By the restriction of objective conditions, students including those from poor areas are appealing to work in the well-developed areas with good traffic and sound health care system. Under free competition employment system, Shizong medical staff's low quality problem is yet not to be solved.

\section{Establishing practicable rural medical security system}

\subsection{Government should monitor medical system}

In order to prevent regulation failure, improve rural medical security system quality and protect patient right, government mechanism should be introduced to manage and supervise the health care industry. In rural medical security system, government not only should increase investment, but also strengthen administration supervision. The administration department should focus on developing and restricting medical market to solve the contradiction of demand and supply in rural health care service. Also, village and county public finance should be under strict control and public supervision, in case of any forms of corruption and wasting.

\subsection{Increasing human resource in rural health care system}

Health care human resource should be continually educated through multiple channels and forms. Due to the diversity of age, qualification, education, and other aspects, transforming from village doctors to general doctors to meet the demand of local service requires full time to accept the academic education, correspondence training in the post, operation system lecture combination, adult self-examination, education to superior unit, receiving help from professionals, and so on.

\subsection{Developing a rural medical aid system}

Medical aid system is an important part of social security system in China, which can provide the help for patients who are too poor to pay for the medical treatment. To accomplish the project of poor people's medical aid, the reality that China is still in the primary stage of socialism and imbalanced development should be fully considered. The achievement of medical aid project has not been enough for the need, and the aid system should be improved on the top agenda.

\section{Conclusion}

Through the survey and case study of Shizong rural medical security system, it can be observed that medical security system is being improved gradually through practice, although there are some problems in present medical system. In response to the practice of "new 
rural cooperative medical security system", the implementation scheme should practically emphasize on the sophisticated function of system structure, widespread enrollment and the harmony of system assistance.

In the future exploration and research of the best operation method in fitting into Chinese rural medical security system, it should be noticed that social insurance system and business insurance system can not be replaced by cooperative medical system under the present economy and system circumstance, but in the near future, may become a part of rural medical security system. What the most effective system arrangement is and whether social insurance system and medical insurance system can better solve the problem of rural medical security should be researched further.

\section{References}

[1] Xingzhen, X. Historical Review of China's Rural Cooperative Medical Security System [J]. Journal of Contemporary China History Studies, 2003, (03)（In Chinese)

[2] Deyuan, Z. Overview and Analysis of China's rural health care development [J]. Journal of Hunan Institute of Science and Technology, 2005, (05) (In Chinese).

[3] Fang, L. Problem Research of China's Medical Security System Reform. Retrieved from http://wenku.baidu.com/view/08f175c59ec 3d5bbfd0a74fd.html. (In Chinese)

[4] Yongshun, F. Analysis and countermeasures of current situation of new rural cooperative medical security system in Panlong District, Kunming [J]. China Primary Health Care, 2010, (10) (In Chinese)

[5] Jianbo, Z. \& Yuan, L. First Exploration of China's rural medical security system model---based on the analysis of new rural cooperative medical security system[J]. Financial Research, 2011, (04)（In Chinese )

[6] Lipin, G. Shandong new rural cooperative medical investigation $[\mathrm{J}]$. Population Publication, 2006, (01) (In Chinese )

[7] Guizhi, L. Jilin operation analysis of new rural cooperative medical security system [J]. Tax and Economy, 2008, (04) (In Chinese)

[8] The outline for China's rural primary health care program development (2001-2010)[M]. 29 Apr. 2004. Retrieved from http://www.moh.gov.cn/publicfiles/busines s/htmlfiles/mohncwsgls/s3577/200804/311 23.htm（In Chinese)

[9] The notice of the opinions of health department in establishing NCMS forwarded by the general office of the state council. 10 Jan. 2003. Retrieved from http://www.chinaacc.com/new/63/74/2003/ 1/ad7387345011161130022538.htm（In Chinese )

[10] http://www.ynsz.gov.cn/sz.htm 